\title{
PRINZMETAL ANGINA IN A YOUNG PATIENT WITH ESSENTIAL THROMBOGYTHEMIA, AFTER ANAGRELIDE INITIATION - CASE REPORT AND LITERATURE REVIEW
}

\section{Matei Luminita9, , Cojocaru Lucia ${ }^{12}$, Ghinea Mihaela ${ }^{1,3}$}

${ }^{1}$ Faculty of Medicine, University "Ovidius" of Constanța

${ }^{2}$ Emergency Clinical Hospital of Constanța, Cardiology Clinic

${ }^{3}$ Emergency Clinical Hospital of Constanța, $2^{\text {nd }}$ Medical Clinic, Hematology Department

\begin{abstract}
We report a case of Prinzmetal angina as inaugural manifestation of coronary disease, in a young adult male patient, recently started on anagrelide for essential thrombocythemia. Moderate proximal left anterior descendent coronary artery stenosis was documented by angiography, and interventional or surgical revascularization has been discussed. Patient's option was for medical therapy alone. Anagrelide was temporarily withdrawn and rechallenged uneventfully after a couple of months and clinical evolution is good at four years follow-up. The mechanism by which anagrelide could induce coronary spasm and ischemia remains to be clarified.
\end{abstract}

Keywords: coronary spasm, Prinzmetal angina, anagrelide, esential thrombocytopenia

\section{Introduction}

Essential thrombocythemia (ET) is a myeloproliferative disorder characterized by an abnormal megacaryocyte proliferation and an elevated platelet count, in the absence of reactive thrombocytosis, other chronic myeloproliferative disorders or a myelodysplastic syndrome (1). Thrombotic and hemorrhagic complications have been noted, and the former are a major cause of morbidity and mortality. Cytoreductive therapy is indicated for thrombosis prevention in high risk cases, and is usually obtained with hydroxyurea, interferon or anagrelide $(1,2)$.

Cardiovascular (CV) adverse effects of anagrelide are frequent, but usually benign, related to vasodilation induced by anti-cyclic Adenosine Monophosphate (AMP) phosphodiesterase activity; more severe secondary reactions, like heart failure, arrhythmia and acute coronary syndromes, have also been associated with anagrelide treatment (3-7), although the causality was not clearly demonstrated.

\section{Gase report}

A 48-year old male patient was reffered for cardiology evaluation from the hematology department, accusing de novo exertion angina. The symptoms started about one week before 
presentation, and manifested as moderate retrosternal discomfort during mild exertion, mainly in the morning, accompanied by sweating and nausea. The complaints improved after rest or sublingual nitroglycerin. $\mathrm{He}$ is a smoker of 20 pack-years, with no family history of cardiovascular or hematologic disease, and was diagnosed 3 years ago with ET, based on current criteria: persistent thrombocytosis (in his case, in the range of 1.200 .000 to 1.800 .000 platelets per microliter), exclusion of a reactive state and absence of another myeloprolipherative disorder, as demonstrated by bone marrow aspiration and absence of Philadelphia chromosome. He had no episodes of thrombosis and occasionally presented mild epistaxis. Cytoreduction was eficiently obtained with anagrelide $2 \mathrm{mg}$ daily; he was previously treated with interferon which was replaced two weeks earlier because of bad tolerance and hydroxyurea which previously stopped due to gastrointestinal upset and patients concer apout its leukemogenic potential.

The physical exam revealed a patient with a good general condition and a body mass index of $25.3 \mathrm{~kg} / \mathrm{m} 2$. The blood pressure was $130 / 80$ $\mathrm{mmHg}$, and the heart beat was regular, with a frequency of $80 / \mathrm{min}$. No cardiac murmurs, gallop or pericardial friction rub were audible. The lungs were clear and no systemic stasis was detectable. Bilateral radial and tibial pulsations were palpable.

Complete blood count was normal, except from a discrete increase in platelet count to 450.000 per microliter. Plasma biochemistry showed normal myocardial necrosis markers, glucose, renal and liver function and ions; total and LDL cholesterol were slightly elevated (220 and $132 \mathrm{mg} / \mathrm{dl}$ respectively), with normal triglycerides.

Resting electrocardiogram (ECG) disclosed sinus rhythm, normal QRS morphology and 0.5 mm ST segment depression in midprecordial leads (Figure 1). Chest X-ray was unremarkable and echocardiography showed a normal sized left ventricle with good contractility, normal valves and no pericardial fluid.

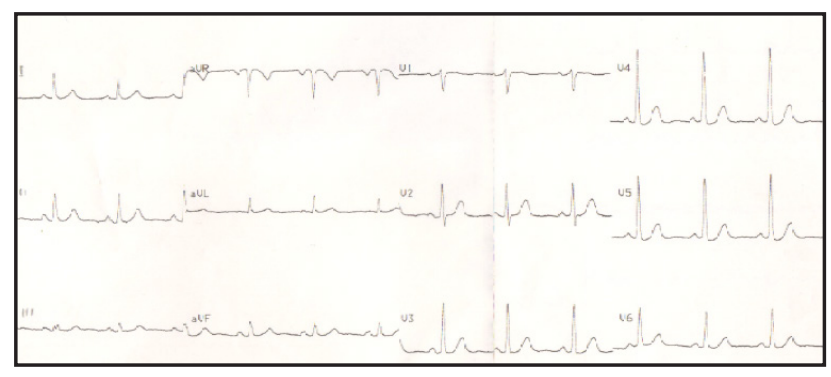

Figure 1. Resting electrocardiogram. Normal sinus rhythm, slight ST depression in leads V4-V5

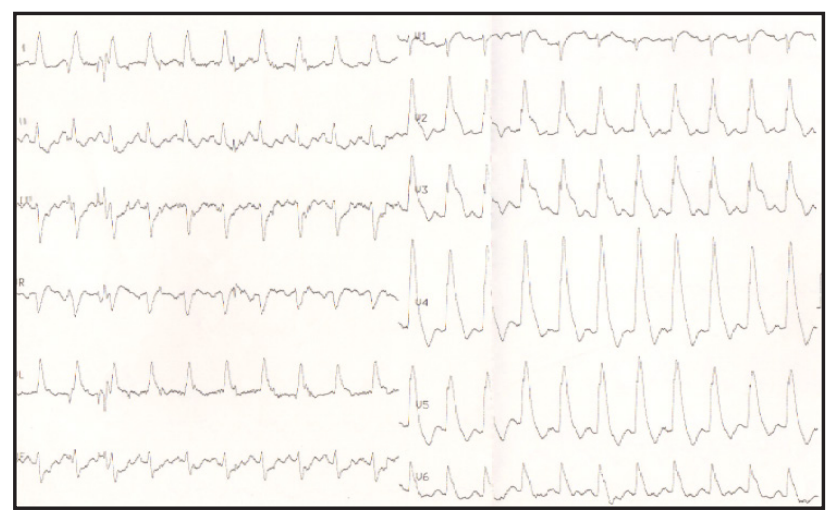

Figure 2. Electrocardiogram at peak effort (7 MET). Sinus tachycardia 120/min, ST elevation in leads V1-V3; giant $R$ wave and monophasic QRS-ST complex in leads V4-V6.

Stress ECG (Bruce protocol) was stopped at the second stage (7 MET) because of important ST segment elevation in precordial leads (Figure 2 ), while the patient reported moderate chest discomfort. Giant $\mathrm{R}$ waves and merging of the QRS complex with the ST segment, causing a monophasic QRS-ST complex have been also noted; these changes were more obvious after the first minute of rest (Figure 3, Figure 4). The pain and the major ECG findings gradually subsided in about fifteen minutes, after repeated sublingual nitroglycerine administration. No significant troponin increase was documented during the next hours, and the diagnosis of Prinzmetal angina was established. 


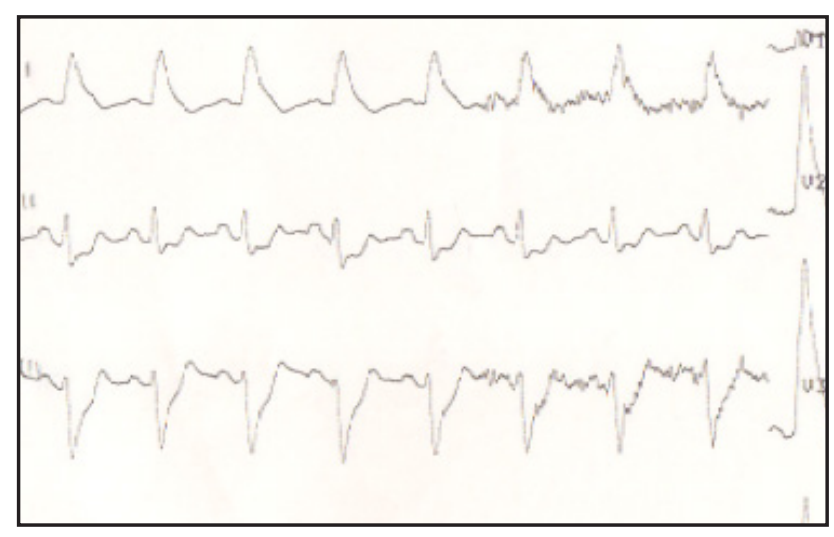

Figure 3. Electrocardiogram in the recovery phase-one minute rest: sinus tachycardia 112/min; giant $R$ waves and monophasic QRS-ST complexes are present in most of the leads

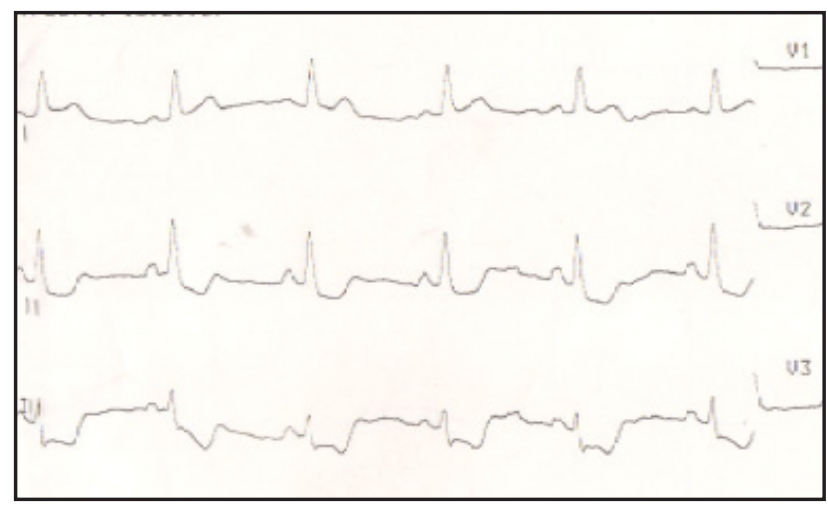

Figure 4. Electrocardiogram in the recovery phase three minutes rest: sinus rhythm, 75/min; no monophasic QRS complexes; ST elevation in leads V1-V5, with reciprocal depression in inferior leads and V6. The aspect masquerades a classical acute anterior myocardial infarction.

The patient stopped smoking and was started on aspirin $100 \mathrm{mg}$, atorvastatin $20 \mathrm{mg}$, verapamil up-titrated to $480 \mathrm{mg}$ (at bed-time), and isosorbide mononitrate $40 \mathrm{mg}$ daily. Angina appeared more rarely subsequently. Due to recent anagrelide initiation, the drug was considered to be a potentially causative agent, and it was temporary replaced by hydroxyurea.

Coronarography revealed a single coronary vessel disease, with a $60-70 \%$ diffuse stenosis of the first segment of the left anterior descending artery (LAD), involving also the bifurcations with the first diagonal and septal branches (Figure 5). Intracoronary nitroglycerine injection did not improve the obstruction. Coronary artery by-pass graft surgery or angioplasty with a drug eluting stent implantation have been discussed. The patient refused any intervention, continued the medical therapy alone, and remained with one or two episodes of mild angina weekly; he appreciates his life quality as good. Anagrelide was rechallenged two months later without angina aggravation. Holter ECG showed a few episodes of ST elevation, but no malignant ventricular arrhythmia. At four years of followup, the patient is stable as concerns both angina and the haematological aspect.

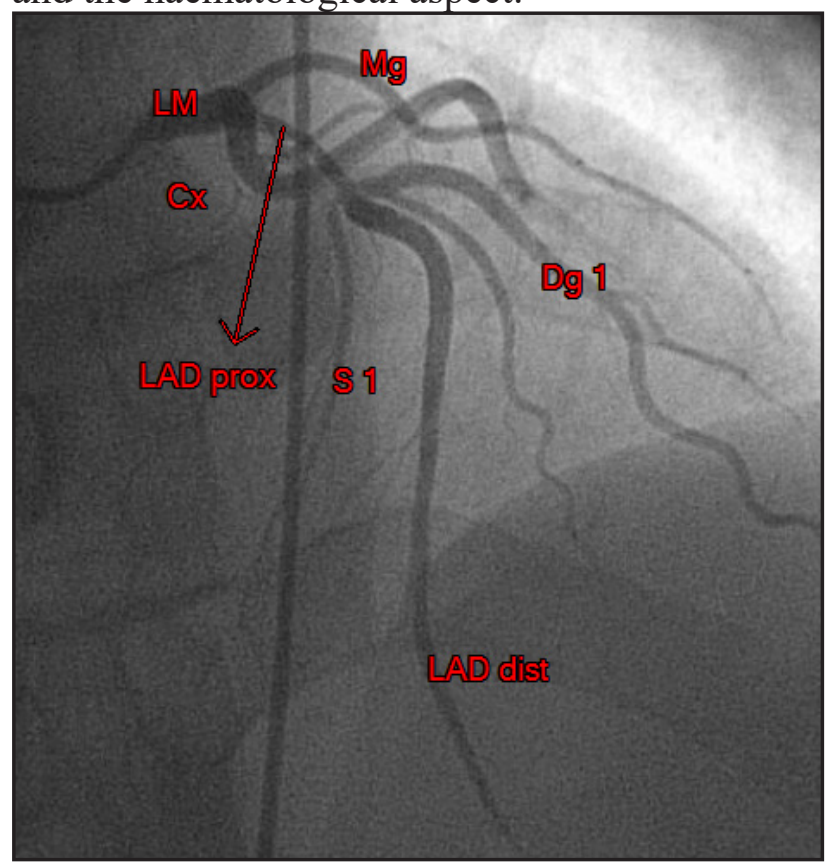

Figure 5. Coronary angiography - 60-70\% diffuse stenosis of the proximal left anterior descending artery (LAD prox). LM = left main coronary artery; LAD dist = distal left anterior descending artery; $C x=$ circumflex artery; $M g$ = left marginal artery; Dg1 = first diagonal artery; $S 1$ = first septal artery.

\section{Discussions}

ET is frequently asymptomatic or the patients report vasomotor symptoms like headache, lightheadedness, syncope, atypical chest pain, acral paresthesia, livedo reticularis, erythromelalgia or transient visual disturbances (8). Although ET does not significantly affect the life expectancy, both thrombotic and hemorrhagic complications have been documented; thrombotic events, more frequent arterial, are the most feared (9). The cumulative probability of thrombosis at $15-20$ years was $17-52 \%$ in large cohorts, even when the majority of the patients were treated with cytoreductive agents and aspirin $(10,11)$. The cerebrovascular circulation is the most 
common site of arterial thrombotic disease, followed by the coronary arteries and peripheral vasculature (12). Venous thromboembolism is also an encountered complication of ET (2).

Cytoreductive therapy for thrombosis prevention in ET is indicated in patients with high risk features, as are: age older than 60 years, history of prior thrombosis, extreme thrombocytosis, and, probably, JAK2V617F mutation (13). Thromboreduction is usually obtained with hydroxyurea, interferon or anagrelide $(13,14)$. There is some debate about the potential leukemogenicity of hydroxyurea, but current evidence does not attribute to the drug a definite risk in this regard; actually, transformation to acute myeloid leukemia is considered part of the natural history of myeloproliferative disorders $(1,15)$.

Anagrelide is an oral imidazoquinazoline derivative that interferes with megakaryocyte proliferation and maturation (16). Toxicity of anagrelide is mainly related to the drug's anticyclic AMP phosphodiesterase activity, resulting in direct vasodilatory and inotropic effects, with consecutive headache, palpitations, tachycardia and fluid retention. This type of side effects is dose-related and diminishes after the first months of treatment (17). Observational studies and case reports revealed also occasional serious CV adverse effects (Table I) associated with anagrelide, like high output heart failure, acquired idiopathic cardiomyopathy, coronary spasm and acute myocardial infarction in patients without traditional coronary disease risk factors (3-7, 18,19). In a retrospective study, almost one third of the anagrelide treated patients experienced CV adverse events, but the majority of these side effects were mild and in only $3.9 \%$ of the patients led to treatment discontinuation (3). Caution is needed when adjudicating the potential adverse effects of a drug used to treat a condition that was by itself associated with acute coronary syndromes due to coronary thrombosis and/or spasm (20-28).

Anagrelide must be used with reserve in patients with known or suspected heart disease; a CV evaluation seems prudent before anagrelide initiation, although it was noted that cardiac adverse events were not related to traditional coronary risk factors and not predictable by previous instrumental evaluation $(1,3)$.

Table I. Cardiovascular adverse reactions associated with anagrelide treatment

\begin{tabular}{|l|l|l|}
\hline Adverse reaction & Frequency & $\begin{array}{l}\text { Refference } \\
\text { index }\end{array}$ \\
\hline Palpitations & $24,1-26 \%$ & 3,17 \\
\hline Tachycardia & $8-35 \%$ & 4,17 \\
\hline Edema & $7,7-21 \%$ & 4,17 \\
\hline Headache & $7,7-44 \%$ & 4,17 \\
\hline Dizziness & $15 \%$ & 17 \\
\hline $\begin{array}{l}\text { Postural hypotension, } \\
\text { syncope, vasodilation }\end{array}$ & Not stated & 17 \\
\hline Arterial hypertension & $3,5 \%$ & 3 \\
\hline Dyspnea & $12 \%$ & 17 \\
\hline Chest pain & $8 \%$ & 17 \\
\hline Angina & $4,3 \%$ & 3 \\
\hline Arrhythmia & $1,8 \%$ & 3 \\
\hline $\begin{array}{l}\text { Acute myocardial } \\
\text { infarction }\end{array}$ & $0,9 \%$ & 3 \\
\hline & Case reports & 4,7 \\
\hline Coronary spasm & Case reports & 4,18 \\
\hline Congestive heart failure & $3 \%$ & 3 \\
\hline Cardiomyopathy & Case reports & $4-6$ \\
\hline Pericardial effusion & $0,4 \%$ & 3 \\
\hline Total & $30 \%$, most of \\
them mild & 3 \\
\hline $\begin{array}{l}\text { Severe enough to need } \\
\text { discontinuation }\end{array}$ & $3,9 \%$ & 3 \\
\hline
\end{tabular}

The mechanisms by which anagrelide induces coronary artery spasm and ischemia are incomplete clarified, as long as inhibition of cyclic AMP phosphodiesterase III induces mainly vasodilator and positive inotropic effects. The drug has also an antiaggregant action, but this is significant only at higher doses than those required to reduce platelet count (18).

Prinzmetal (variant, vasospastic) angina is characterized by transient ST elevation during the acute attack, without significant troponin increase. The coronary spasm is probably caused by a blunted endothelial function that cannot balance with flow-mediated vasodilation the nonspecific vasoconstrictor stimuli such 
as catecholamine, serotonin, histamine, thromboxane A2 and endothelin at the vascular smooth muscle level (29).

Coronary spasm is usually focal and tends to recur at the same location, generally at the site of an atherosclerotic lesion (29). However, coronary spasm can be multifocal or diffuse and can affect coronary arteries that appear normal on coronary angiography (29). In such cases intravascular ultrasound and necroscopy almost always reveal angiographically silent atherosclerosis at the site of the spasm (29).

If the typical ECG pattern can not be spontaneously demonstrated, but suspicion persists based on the circadian variation of angina, provocation tests as hyperventilation, cold pressor test or intracoronary acetylcholine/ ergonovine can be implemented.

Exercise treadmill testing is of limited value in variant angina, but exercise-induced spasm can occur, as it was the case in our patient. Generally speaking, ST elevation is a rare finding in ECG treadmill testing, (about 3.5\% of patients), and $90 \%$ of them have critical LAD lesions; in only a minority, the coronary spasm is the dominant contributor to ischemia (30). Electrocardiographic leads with ST-segment elevation have a good prediction value for the site of hypoperfusion and the same observation was valid in our case (31). The particular ECG aspect of giant R and monophasic QRS-ST complex may be rarely observed, except from variant angina, in acute myocardial infarction and after percutaneous transluminal coronary angioplasty (32).

Therapeutic options for vasospastic angina. The medical treatment of Prinzmetal angina is based on calcium channel inhibitors, long acting nitrates, and possibly the newer Rho-kinase inhibitor, fasudil (33). Beyond this, the management of the cases with associated significant atherosclerotic coronary lesion is not standardized. For critical coronary stenosis (more than $90 \%$ ), there is no doubt that revascularization is mandatory, similarly with the general patients with coronary heart disease. Good clinical evolution has been described after coronary artery by-pass grafting (34) as well as after stent placement in Prinzmetal angina with significant LAD stenosis (35). On the contrary, the role of coronary revascularization in the treatment of vasospastic angina without important coronary stenosis is limited, since coronary spasm was frequently induced at a site different from the initial stenosis, even in the absence of restenosis after coronary stent placement (36). The only Prinzmetal angina dedicated guidelines, the Japanese ones, advise against revascularization in patients without severe coronary lesion (37).

WejudgedourcaseaccordingtotheEuropean Guidelines on Myocardial Revascularization, that recommend revascularization as a class I indication for prognosis reason in any proximal LAD stenosis of more than $50 \%$; the available options are angioplasty or coronary artery bypass graft surgery (38).

The role of anagrelide as a trigger for coronary spasm in our case is debatable. The short time elapsed between drug initiation and angina onset remains clearly a query and it has been noted that the adverse effects of anagrelide are more frequent in the first months of treatment (17). On the other side, Prinzmetal angina appears typically in younger, smoker, male patients with no other major coronary risk factors; and spontaneous remission is a frequent outcome of variant angina (39).

The decision to restart anagrelide in our patient was controversial, but from the haematologist point of view, there were no other better options available for thromboreduction, as long as hydroxyurea and interferon were already bad tolerated. The general opinion is that, although the reduction of side effects might occur over time, anagrelide should be discontinued in patients who experience life-threatening adverse events $(4,7,13)$. A more permissive approach is suggested by a case report, presenting a successful rechallenge with anagrelide in a patient with anagrelide-associated cardiomyopathy, after left ventricular function recovery (40).

Prognostic considerations. The natural history of Prinzmetal angina with no severe coronary lesion is generally good as long as patients avoid cigarette smoking and have good compliance with calcium antagonists therapy (33). Patients without a coronary stenosis of $70 \%$ or more, have a 94\% 1-year myocardial infarctionfree survival rate (33). Myocardial infarction is more frequent in patients with severe (more 
then $90 \%$ ) fixed coronary stenosis. Seventy-five percent of nonfatal myocardial infarction occurs during the first three months after symptom onset or aggravation (33). Sudden cardiac death remains an uncommon but not negligible threat for patients with Prinzmetal angina, especially for those who continue to smoke, or stop calcium channel antagonists. A study reported $2 \%$ sudden deaths during a three year follow up; the event was not correlated with fixed coronary stenosis (41). Implantable cardioverter defibrillators were sometimes necessary in patients with vasospastic angina and severe rhythm disturbances, even after coronary revascularization and/or correct medical treatment $(42,43)$.

\section{Conclusions}

We reported this case to underline that anagrelide can be associated with severe cardiovascular adverse effects, although the majority of these side effects are benign. Taken this fact into account a cardiovascular evaluation needs to be done before anagrelide initiation especially in patients with known or suspected heart disease. If the side effects are not severe, anagrelide can be continued as their reduction might occur over time; in patients who experience life-threatening adverse events anagrelide should be discontinued. Anagrelide can be successfully rechallenged, after the recovery from its side effects, especially if other therapeutic options are unavailable.

\section{Acknowledgements:}

We thank all members of the medical team and the patient.

\section{References}

1. Vannucchi AM, Guglielmelli P, Tefferi A. Advances in understanding and management of myeloproliferative neoplasms. CA: a cancer journal for clinicians. 2009 May 1;59(3):171-91.DOI: 10.3322/caac.20009.

2. De Stefano V, Za T, Rossi E, Vannucchi AM, Ruggeri M, Elli E, Micò C, Tieghi A, Cacciola RR, Santoro C, Gerli G. Recurrent thrombosis in patients with polycythemia vera and essential thrombocythemia: incidence, risk factors, and effect of treatments. haematologica. 2008 Mar 1;93(3):372-80. DOI: 10.3324/haematol.12053

3. Gugliotta L, Tieghi A, Tortorella G, Scalzulli PR, Ciancia R, Lunghi M, CacciolaE, Cacciola R, Candoni A, Crugnola M, Codeluppi K. Low impact of cardiovascular adverse events on anagrelide treatment discontinuation in a cohort of 232 patients with essential thrombocythemia. Leukemia research. 2011 Dec 1;35(12):1557-63. DOI: https://doi. org/10.1016/j.leukres.2011.06.030.

4. Mazzucconi MG, Redi RO, Bernasconi SA, Bizzoni L, Dragoni FR, Latagliata R, Santoro CR, Mandelli FR. A long-term study of young patients with essential thrombocythemia treated with anagrelide. Haematologica. 2004 Jan 1;89(11):1306-13.

5. Jurgens DJ, Moreno-Aspitia A, Tefferi A. Anagrelide-associated cardiomyopathy in polycythemia vera and essential thrombocythemia. Haematologica. 2004 Jan 1;89(11):1394-5.

6. Proietti R, Rognoni A, Ardizzone F, Maccio S, Santagostino A, Rognoni G. Atypical Takotsubo syndrome during anagrelide therapy. Journal of Cardiovascular Medicine. 2009 Jul 1;10(7):546-9. DOI: 10.2459/ JCM.0b013e32832b7f08.

7. Lim YH, Lee YY, Kim JH, Shin J, Lee JU, Kim KS, Kim SK, Kim JH, Lim HK. Development of acute myocardial infarction in a young female patient with essential thrombocythemia treated with anagrelide: a case report. The Korean journal of hematology. 2010 Jun 1;45(2):136-8. DOI: 10.5045/kjh.2010.45.2.136.

8. Teffer A. Diagnosis and clinical manifestations of essential thrombocythemia [Internet]. Uptodate.com. 2012 [cited May 2017]. Available from: https:// www.uptodate.com/contents/diagnosisand-clinical-manifestations-of-essentialthrombocythemia?search=Diagnosis $\% 20$ and $\% 20$ clinical $\% 20$ manifestations $\% 20$ of $\% 20$ essentia $1 \% 20$ thrombocy $\mathrm{th}$ e mi a \& s o u r c e $=\mathrm{s}$ e a r c h result\&selectedTitle $=1 \sim 57 \&$ usage type $=$ default $\&$ display_rank $=1$. 
9. Tefferi A, Elliott M. Thrombosis in myeloproliferative disorders: prevalence, prognostic factors, and the role of leukocytes and JAK2V617F. InSeminars in thrombosis and hemostasis 2007 Jun (Vol. 33, No. 04, pp. 313-320). Copyright $(\mathrm{C} 2007$ by Thieme Medical Publishers, Inc., 333 Seventh Avenue, New York, NY 10001, USA.. DOI:10.1055/s-2007-976165.

10. Passamonti F, Rumi E, Pungolino E, Malabarba L, Bertazzoni P, Valentini M, Orlandi E, Arcaini L, Brusamolino E, Pascutto C, Cazzola M. Life expectancy and prognostic factors for survival in patients with polycythemia vera and essential thrombocythemia. The American journal of medicine. 2004 Nov 15;117(10):755-61. DOI:10.1016/j.amjmed.2004.06.032

11. Wolanskyj AP, Schwager SM, McClure RF, Larson DR, Tefferi A. Essential thrombocythemia beyond the first decade: life expectancy, long-term complication rates, and prognostic factors. InMayo Clinic Proceedings 2006 Feb 1 (Vol. 81, No. 2, pp. 159-166). Elsevier. DOI:10.4065/81.2.159.

12. Bleeker JS, Hogan WJ. Thrombocytosis: Diagnostic Evaluation, Thrombotic Risk Stratification, and Risk-Based Management Strategies. Thrombosis. 2011;2011:16. http://dx.doi.org/10.1155/2011/536062.

13. Barbui T, Finazzi MC, Finazzi G. Frontline therapy in polycythemia vera and essential thrombocythemia. Blood reviews. 2012 Sep 1;26(5):205-11. DOI: 10.1016/j. blre.2012.06.002.

14. Emadi A, Spivak JL. Anagrelide: 20 years later. Expert review of anticancer therapy. 2009 Jan 1;9(1):37-50. DOI: 10.1586/14737140.9.1.37.

15. Fruchtman SM, Petitt RM, Gilbert HS, Fiddler G, Lyne A. Anagrelide: analysis of long-term efficacy, safety and leukemogenic potential in myeloproliferative disorders. Leukemia research. 2005 May 1;29(5):48191. DOI:10.1016/j.leukres.2004.10.002.

16. Tomer A. Effects of anagrelide on in vivo megakaryocyte proliferation and maturation in essential thrombocythemia. Blood. 2002 Mar 1;99(5):1602-9. DOI: https://doi. org/10.1182/blood.V99.5.1602.
17. Storen EC, Tefferi A. Long-term use of anagrelide in young patients with essential thrombocythemia. Blood. 2001 Feb 15;97(4):863-6. DOI: 10.1182/blood. V97.4.863.

18. Anagrelide. Drug Information. UpToDate 2012Retrieved December 11, 2017 from www.UpToDate.com, version 17.3.

19. Lin GM, Chao TY, Wang WB. Acute coronary syndromes and Anagrelide. International journal of cardiology. 2007 Apr 12;117(1):e17-9. DOI:10.1016/j. ijcard.2006.07.079.

20. Kumagai N, Mitsutake R, Miura SI, Kawamura A, Takamiya Y, Nishikawa H, Uehara Y, Saku K. Acute coronary syndrome associated with essential thrombocythemia. Journal of cardiology. 2009 Dec 1;54(3):4859. doi: 10.1016/j.jjcc.2009.03.001.

21. Watanabe T, Fujinaga H, Ikeda Y, Higashi T, Murakami M, Kawahara K, Hayashi I, Niki T, Shigekiyo T, Wakatsuki T. Acute myocardial infarction in a patient with essential thrombocythemia who underwent successful stenting: a case report. Angiology. 2005 Nov;56(6):771-4. DOI:10.1177/000331970505600616.

22. Fujimura M, Akaike M, Kato M, Takamori N, Abe M, Nishiuchi T, Azuma H, Matsumoto T. Aggressive antiplatelet therapy before coronary stent implantation in acute coronary syndrome with essential thrombocythemia: a case report. Angiology. 2003 Jul;54(4):48590. DOI:10.1177/000331970305400414.

23. Turgut T, Harjai KJ, Edupuganti R, Cole J, Jenkins JS, Ramee SR, Collins TJ. Acute coronary occlusion and in-stent thrombosis in a patient with essential thrombocythemia. Catheterization and Cardiovascular Interventions. 1998 Dec 1;45(4):428-33. DOI:10.1002/ (SICI)1097-0304(199812)45:4<428::AIDCCD19>3.0.CO;2-E.

24. Ozben B, Ekmekci A, Bugra Z, Umman S, Meric M. Multiple coronary thrombosis and stent implantation to the subtotally occluded right renal artery in a patient with essential thrombocytosis: a case report with review. Journal of thrombosis and thrombolysis. 2006 Aug 1;22(1):79-84. DOI:10.1007/ 
s11239-006-7790-8.

25. Daya SK, Gowda RM, Landis WA, Khan IA. Essential thrombocythemia-related acute ST-segment elevation myocardial infarction: A case report and literature review. Angiology. 2004 May;55(3):319-23. DOI:10.1177/000331970405500312.

26. Koh KK, Cho SK, Kim SS, Oh BH, Lee YW. Coronary vasospasm, multiple coronary thrombosis, unstable angina and essential thrombocytosis. International journal of cardiology. 1993 Sep 1;41(2):16870. DOI: https://doi.org/10.1016/01675273(93)90158-D.

27. Choi HS, Jeong MH, Seo IK, Lee MG, Ko JS, Park KH, Sim DS, Yoon NS, Kim KH, Park HW, Hong YJ. Very late stent thrombosis in a drug-eluting stent due to interruption of anti-platelet agents in patients with acute myocardial infarction and thrombocytosis. Korean circulation journal. 2011 Jul 1;41(7):417-20. doi: 10.4070/ kcj.2011.41.7.417.

28. Rugină M, Predescu L, Molfea V, Coman IM, Bubenek-Turconi Ş. Afectarea cardiacă în cadrul trombocitemiei esenţiale--review. Romanian Journal of Cardiology. 2011 Sep $1 ; 21(3)$.

29. Nardi F, Verna E, Secco GG, Rognoni A, Bongo AS, Iraghi G, Bertuol S, Lupi A. Variant angina associated with coronary artery endothelial dysfunction and myocardial bridge: a case report and review of the literature. Internal Medicine. 2011;50(21):2601-6. DOI:https://doi. org/10.2169/internalmedicine.50.6086.

30. Chahine RA, Raizner AE, Ishimori $T$. The clinical significance of exerciseinduced ST-segment elevation. Circulation. 1976;54(2):209-13. DOI: https://doi. org/10.1161/01.CIR.54.2.209

31. Gallik DM, Mahmarian JJ, Verani MS. Therapeutic significance of exerciseinduced ST-segment elevation in patients without previous myocardial infarction. The American journal of cardiology. 1993;72(1):1-7. DOI: https://doi. org/10.1016/0002-9149(93)90209-U.

32. Testa-Fernández A, Rios-Vazquez R, SieiraRodríguez-Moret J, Franco-Gutierrez R,
Peña-Gil C, Pérez-Fernández R, Puebla-Rojo V, Regueiro-Abel M, Gonzalez-Juanatey C. " Giant R wave" electrocardiogram pattern during exercise treadmill test: A case report. Journal of medical case reports. 2011 Dec;5(1):304. DOI: 10.1186/1752-1947-5304.

33. Hung MJ. Current advances in the understanding of coronary vasospasm. World journal of cardiology. 2010 Feb 26;2(2):3442.DOI: $10.4330 / w j c . v 2 . i 2.34$.

34. Shin DI, Horlitz M, Haltern G, Krölls W, Coll M, Bufe A, Lapp H, Gülker H. Therapieoptionen einer Prinzmetal-Angina induzierten ventrikulären Vulnerabilität. Zeitschrift für Kardiologie. 2003 Apr 1;92(4):332-8. DOI:10.1007/s00392-0030916-5.

35. Maeder M, Ammann P, Angehrn W, Rickli H. A case of coronary vasospasm treated with stent placement. Zeitschrift fur Kardiologie. 2003 Feb;92(2):182-7. DOI:10.1007/ s00392-003-0882-y.

36. Tanabe Y, Itoh E, Suzuki K, Ito M, Hosaka Y, Nakagawa I, Kumakura M. Limited role of coronary angioplasty and stentingin coronary spastic angina with organic stenosis. Journal of the American College of Cardiology. 2002 Apr 3;39(7):1120-6. DOI:https://doi. org/10.1016/S0735-1097(02)01746-1.

37. JCS Joint Working Group. Guidelines for diagnosis and treatment of patients with vasospastic angina (Coronary Spastic Angina)(JCS 2013). Circulation Journal. 2014 Oct 24;78(11):2779-801. DOI: 10.1253/circj.CJ-66-0098.

38. Windecker S, Kolh P, Alfonso F, Collet JP, Cremer J, Falk V, Filippatos G, Hamm C, Head SJ, Jüni P, Kappetein AP. Authors/ Task Force members. 2014 ESC/EACTS guidelines on myocardial revascularization: the task force on myocardial revascularization of the European Society of Cardiology (ESC) and the European Association for CardioThoracic Surgery (EACTS) developed with the special contribution of the European Association of Percutaneous Cardiovascular Interventions (EAPCI). Eur Heart J. 2014 Oct 1;35(37):2541-619.DOI:10.1093/eurheartj/ ehu278. 
39. Gaetano A, Crea F. Vasospastic angina [Internet]. Escardio.org. 2013 [cited 12 January 2018]. Available from: https:// www.escardio.org/Journals/E-Journal-ofCardiology-Practice/Volume-2/VasospasticAngina-Title-Vasospastic-Angina

40. Wong RS, Lam LW, Cheng G. Successful rechallenge with anagrelide in a patient with anagrelide-associated cardiomyopathy. Annals of hematology.2008 Aug 1;87(8):6834. DOI: $10.1007 / \mathrm{s} 00277-008-0451-6$.

41. Nakamura MO, Takeshita A, Nose Y. Clinical characteristics associated with myocardial infarction, arrhythmias, and sudden death in patients with vasospastic angina. Circulation. 1987 Jun 1;75(6):1110-6. DOI: https://doi. org/10.1161/01.CIR.75.6.1110.

42. Dresen WF, Wells QS, Maron DJ, McPherson JA. Therapeutic procedures for coronary vasospasm-induced polymorphic ventricular tachycardia. Therapeutic advances in cardiovascular disease. 2012 Jun;6(3):11521. DOI: $10.1177 / 1753944712446303$.

43. MatsueY,SuzukiM,NishizakiM\&al.Clinical implications of an implantable cardioverterdefibrillator in patients with vasospastic angina and lethal ventricular arrhythmia. J Am Coll Cardiol. 2012; 60(10):908-913. DOI: $10.1016 /$ j.jacc.2012.03.070. 